\title{
Symptomatic submucous uterine fibroid: outcome of conservative surgery in a tertiary care hospital
}

\author{
Pratiksha Gupta* \\ Department of Obstetrics and Gynecology, PGIMSR, ESI, Basaidarapur, New Delhi, India
}

Received: 24 January 2016

Accepted: 02 March 2016

\author{
*Correspondence: \\ Dr. Pratiksha Gupta, \\ E-mail: drpratiksha@gmail.com
}

Copyright: ( $)$ the author(s), publisher and licensee Medip Academy. This is an open-access article distributed under the terms of the Creative Commons Attribution Non-Commercial License, which permits unrestricted non-commercial use, distribution, and reproduction in any medium, provided the original work is properly cited.

\begin{abstract}
Background: Leiomyoma are benign smooth muscle neoplasm's that typically originate from the myometrium. The main objective was to evaluate the outcome of conservative surgical approach for submucous fibroid uterus is using prostaglandin preoperatively and gonadotropin releasing hormone $(\mathrm{GnRh})$ in preoperative phase.

Methods: Thirty eight patients who had hysteroscopic myomectomy with a resectoscope for submucous fibroid were studied at the department of Obstetrics and Gynecology of the Government Medical College, Chandigarh and PGIMSR, New Delhi, India.

Results: Median age was 35 years (20 to 50). Abnormal uterine bleeding (AUB) was the most frequent indication $(71.05 \%)$. Failure to conceive and repeated abortion was indication in $11(28.94 \%)$ cases. GnRH analogue preparation was used in $8(21.05 \%)$ of cases. A median of 37.10 (15 minutes to 60 minutes) minutes was required for the interventions. The myomectomy was combined with another operation in 15 patients. Complete resection was not possible in 4 patients, while 5 underwent a reoperation. No serious complications occurred, with satisfactory followup outcome as AUB was controlled in $89.48 \%$ of the patients.

Conclusions: Hysteroscopic myomectomy is a reliable procedure that is effective in controlling abnormal uterine bleeding, even it can be done in larger submucous fibroid using GnRh analogue, and prostidin.
\end{abstract}

Keywords: Submucous myoma, Fibroid, Hysteroscopic myomectomy, Prostaglandin, Gonadotropin releasing hormone

\section{INTRODUCTION}

Leiomyoma are benign smooth muscle neoplasm's that typically originate from the myometrium. Their incidence among women is generally cited as 20 to 25 percent, but has been shown to be as high as 70 to 80 percent in studies using histological or sonographic examination. ${ }^{1-4}$ Submucous fibroids are the most common anatomical cause of abnormal uterine bleeding in women of reproductive age. Other symptoms related to submucous fibroids are, infertility, and postmenopausal bleeding. Advances in operative hysteroscopy have enabled removal of these lesions with a significant reduction in morbidity, post-operative recovery time and costs compared to open abdominal myomectomy. ${ }^{5}$ This study was conducted to evaluate if large submucous fibroids could be resected in single sitting with surgeons expertise and use of prostaglandin during the procedure.

\section{METHODS}

A prospective study was undertaken from March 2007 to April 2013. The patients admitted for myomectomy for submucous fibroid were taken into consideration. A total of 38 patients were included in the present study. All of them had submucous fibroid.

11 cases had infertility associated. Rest all had menorrhagia. In these patients hysteroscopic myomectomy with a resectoscope was done. Procedures 
were performed in operative theatre of Department of Obstetrics and Gynaecology at the Government Medical Chandigarh and PGIMSR, New Delhi, India.

Pre-operative evaluation was done with transvaginal ultrasound and MRI. Patients were grouped depending on the size of fibroid. Maximum number of cases had a fibroid size between 1-5 cm in size, 8 women had fibroid of size between $9-11 \mathrm{~cm}$. All these had $<50 \%$ intramural extension. All cases were planned for elective hysteroscopic myomectomy. All patients underwent hysteroscopic resection with a monopolar loop. Operating surgeon was common in all these women. $1.5 \%$ glycine was used as the distending media.

Intramuscular prostaglandin injection was used in all the women after excising more than half of the myoma during surgery. Follow up was done up to maximum of 12 months post-surgery.

\section{RESULTS}

Maximum numbers of cases were in the age group of 3040 years $(42.10 \%)$. Seven were between $40-50$ years of age as shown in Table 1 . Out of 38 , twenty seven $(71.05 \%)$ came with abnormal uterine bleeding, 11 $(28.94 \%)$ had primary and secondary infertility related to submucous myoma. Three cases had severe dysmenorrhoea, due to myoma (Table 2). Eight cases had been treated preoperatively with 3 doses of Growth hormone releasing hormone agonist (GNRH), as in these cases menorrhagia had led to severe iron deficiency anaemia prior to surgery. Three had blood transfusion in preoperative phase. Pre-operative evaluation was done with transvaginal ultrasound and MRI.

Table 1: Age distribution.

\begin{tabular}{|llll|}
\hline Age in years & $20-30$ & $30-40$ & $40-50$ \\
\hline $\begin{array}{l}\text { No. of cases } \\
(\%)\end{array}$ & $16(42.10)$ & $14(36.84)$ & $8(21.05)$ \\
\hline
\end{tabular}

Table 2: Symptoms due to fibroid.

\begin{tabular}{|lll|}
\hline $\begin{array}{l}\text { Symptoms } \\
\text { Abnormal uterine } \\
\text { bleeding }\end{array}$ & 27 & 71.05 \\
\hline Infertility & 11 & 28.94 \\
\hline $\begin{array}{l}\text { Severe } \\
\text { dysmenorrhoea }\end{array}$ & 3 & 7.89 \\
\hline
\end{tabular}

Patients were grouped depending on the size of fibroid. Maximum number of cases had a fibroid size between 1$5 \mathrm{~cm}$ in size, in eight cases had fibroid of size between 9$11 \mathrm{~cm}$. Eight cases were type 0 under Wamsteker classification, 26 were type 1 and 5 had type 2 myoma. All cases were planned for elective hysteroscopic myomectomy (Table 3).
Table 3: Grading according to size of fibroid.

\begin{tabular}{|llllll|}
$\begin{array}{l}\text { Sive of } \\
\text { fibroid }\end{array}$ & $1-3 \mathrm{~cm}$ & $3-5 \mathrm{~cm}$ & $5-7 \mathrm{~cm}$ & $7-9 \mathrm{~cm}$ & $9-11 \mathrm{~cm}$ \\
\hline $\begin{array}{l}\text { No. of } \\
\text { patient } \\
(\%)\end{array}$ & 5 & 11 & 10 & 4 & 8 \\
\hline
\end{tabular}

Hysteroscopic myomectomy was done under general anaesthesia, using monopolar loop and $1.5 \%$ glycine. A median of 37.10 (15 minutes to 60 minutes) minutes was required for the interventions. The myomectomy was combined with another operation in 15 patients, two submucous polypectomy, trans endometrial resection of endometrium was done in 4 patients. One had laparoscopic cystectomy. Out of 38 cases, complete surgery in one sitting was possible in 32 cases. We could not complete the resection in 4 patients of type 2 cases. Three required second surgery, they had repeat hysteroscopic myomectomy, one underwent abdominal hysterectomy as this patient was not willing for repeat hysteroscopy, and had completed family and was of 50 years of age. No serious complications (Table 4) occurred in any of the women, and the median hospital stay was 48 hours. The histological study confirmed leiomyoma in all the cases. The intervention results were satisfactory after a follow-up period of 12 months. Abnormal uterine bleeding (AUB) being controlled in $89.48 \%$ of the patients. Two out of 11 patients conceived.

Table 4: Complications due to hysteroscopy resection.

\begin{tabular}{|ll|}
\hline Complications & No. of cases $(\%)$ \\
\hline Second surgery & $4(10.52)$ \\
\hline Perforation & $1(2.63)$ \\
\hline Blood transfusions & $6(15.78)$ \\
\hline Haemorrhage & $2(5.26)$ \\
\hline Urinary tract infection & $3(7.89)$ \\
\hline electrolyte imbalance & 0 \\
\hline Persistent menorrhagia & $4(10.52)$ \\
\hline Recurrence of fibroid & $1(2.63)$ \\
\hline Hysterectomy & $1(2.63)$ \\
\hline Open myomectomy & None \\
\hline
\end{tabular}

During surgery one patient had perforation of uterus which was small and did not required any intervention, 2 had haemorrhage which was controlled by bimanual massage and prostaglandin injection. Six required blood transfusions, 5 required preoperatively and 1 required peroperatively. Post-operative complications were urinary tract infection in 3 cases $(7.89 \%)$. Symptoms of abnormal uterine bleeding persisted only in 4 cases $(10.52 \%)$. One had recurrence of fibroid after 3 months of surgery of but without any abnormal bleeding (Table 4). So patient was reassured. 


\section{DISCUSSION}

The ability to remove these myoma depends on the degree to which myoma are embedded in the myometrium. Various classification are given to grade and grading basically decides the operability, as given by Wamsteker, et al. Type 0 myoma, the myoma completely lies in endometrial cavity are usually easy to remove. Type I lesions that is > than $50 \%$ lies in endometrial cavity and it can often be completely removed as the uterus contracts and tends to expel the intramural component into the uterine cavity during surgery However, removal of type II that is $>50 \%$ lies in intramural part- myoma can be problematic, as fluid overload or fear of perforation may lead to incomplete resection. Wamsteker et al found that the likelihood of achieving a complete removal of type II myoma was only $50 \%$. Although incomplete removal is associated with failure of treatment, there are some reports suggesting that residual tissue may undergo spontaneous regression, without the need for subsequent surgery. ${ }^{5}$ Lasmar too developed a classification system (STEP-w) for hysteroscopic myomectomies based on the degree of technical difficulty in carrying out the procedure and to recommend the most suitable course of action in each situation. According to this classification maximum scores are given to myoma of more than $5 \mathrm{~cm}$, involving upper part of uterus, covering more than $2 / 3$ of surface of uterus, and when more than $50 \%$ lies in intramural part, and involves the lateral wall. Score 0-4 comes under group 1 and the recommendation is low complexity hysteroscopic myomectomy, when the score is 5-6, recommendation is high complexity hysteroscopic myomectomy - GnRH/Two-step hysteroscopic myomectomy. If the score is above 7 , hysteroscopic myomectomy is not indicated. ${ }^{6}$

In present study 38 hysteroscopic myomectomies were undertaken. The patients' median age was 35 years (20 to 50). AUB being controlled in $89.48 \%$ of the patients in present study, similar to study by Wamsteker et al. ${ }^{5}$ In this study bleeding was controlled in 48 (94.1\%) of all patients after final resection. ${ }^{5}$

Hysterectomy was performed in three patients (5.9\%) because of persistent complaints: in two cases after incomplete resection and in one case after complete resection and $6.7 \%$ had a recurrence. In our study hysterectomy was performed in 1 woman, who was not willing for second resection. There was no recurrence in remaining women. As with more extensive intramural involvement, the chance to achieve complete resection decreases and the mean number of procedures to achieve complete resection increases. Complete resection improves the long-term results of transcervical resection of submucous fibroids for control of abnormal uterine bleeding. Transcervical resection of submucous fibroids with more than $50 \%$ intramural extension should be performed only in selected cases, as complete resection usually necessitates repeat procedures. Repeat resection is an option after failed primary hysteroscopic operation and may reduce the hysterectomy rate. In our series 4 women required second resection as they were in group 3 classification and were of size more than $8 \mathrm{~cm}$. In another study after a follow-up period of five years and more, results were satisfactory in $70-85 \%$ of the patients. Prior to hysteroscopic myoma resection, pre-treatment with GnRH agonists was used in this study, as we also used in 8 cases. ${ }^{7}$ It may be indicated in selected cases (large myoma, patients suffering from secondary anemia). The American College of Obstetricians and Gynecologists currently also recommends GnRH agonist therapy as a temporizing agent in women nearing menopause or as surgical pre-treatment in selected women. Preoperatively, GnRH agonists offer several advantages. Their use decreases menorrhagia and may allow correction of anemia. Decreased uterine size as a result of treatment may allow a less-complicated or extensive surgical procedure. Use of gonadotropin-releasing hormone (GnRH) agonists have been shown to improve hematologic parameters, shorten hospital stay, and decrease blood loss, operating time, and postoperative pain when given for 2-3 months preoperatively. Benefits of preoperative use of GnRH agonists should be weighed against their cost and side effects for individual patients. ${ }^{8}$ Operative hysteroscopy is also safe and effective in controlling persistent postmenopausal bleeding and menorrhagia. ${ }^{7-12}$ In infertile women with sub mucosal or intracavitary fibroids, pregnancy and delivery rates are increased after hysteroscopic myomectomy. ${ }^{7}$ Out of 11 patients in our study conceived within 1 year of resection and delivered at full term. In one study hysteroscopic myomectomy was associated with an increase in pregnancy rate $57.1 \%$ for patients with type 0 myoma and $42.8 \%$ for patients with type I myoma. Patients with type II myoma, after hysteroscopic myomectomy, had a $25 \%$ pregnancy rate, while patients who received expectant management had a $50 \%$ rate. Delivery at term was achieved by $35.7 \%$ of patients with type 0 myoma, by $28.5 \%$ of patients with type I myoma, and by $25 \%$ of patients with type II myoma, after hysteroscopic myomectomy. ${ }^{13}$ Other studies also concluded that hysteroscopic leiomyoma resection also improves fertility rates, especially when tumors are the sole cause of infertility. ${ }^{14-16}$ Even uterine artery embolization is an angiographic interventional procedure that delivers particulate emboli into both uterine arteries. Uterine blood flow is therefore obstructed, producing ischemia and necrosis. Embolization is effective for leiomyomarelated symptoms. The American college of obstetricians and gynaecologists currently recommends it for shortterm relief of bleeding or pressure symptoms. Newer modalities as magnetic resonance imaging-guided focused ultrasound (MRI-FUS) therapy is a safe and feasible, minimally invasive alternative for leiomyoma treatment. It may provide short-term symptom relief with the advantage of a quicker recovery and few major adverse events. ${ }^{8}$ 
We used intramuscular prostaglandin injection in all the women after excising more than half of the myoma, which made the intramural fibroid to get more projected into the endometrial cavity, and thus reducing blood loss and helped to completely resect the myoma in most of the cases, even $>9 \mathrm{~cm}$ size, in single sitting.

\section{CONCLUSION}

Hysteroscopic resection is the gold standard for the treatment of symptomatic submucous fibroids. Larger sized submucous myoma can also be resected in single sitting if prostaglandin intramuscular is used during the procedure, and Gonadotropin releasing hormone is used preoperatively, but skilled surgeon is required.

\section{Funding: No funding sources}

Conflict of interest: None declared

Ethical approval: The study was approved by the Institutional Ethics Committee

\section{REFERENCES}

1. Hoffman, Schorge, Schaffer, Halvorson, Bradshaw, Cunningham. Pelvic mass. In Barbaral. Hoffman editor. Textbook of Williams Gynecology, 4th edition. New York: Mc Graw Hill publisher. 2008.246-80.

2. Buttram VC, Reiter RC. Uterine leiomyoma: etiology, symptomatology, and management. Fertil Steril. 1981;36:433.

3. Cramer SF, Patel A. The frequency of uterine leiomyoma. Am J Clin Pathol. 1990;94:435.

4. Day Baird D, Dunson DB, Hill MC. High cumulative incidence of uterine leiomyoma in black and white women: ultrasound evidence. Am J Obstet Gynecol. 2003;188:100.

5. Wamsteker K, Emanuel MH, de Kruif JH. Transcervical hysteroscopic resection of submucous fibroids for abnormal uterine bleeding: results regarding the degree of intramural extension. Obstet Gynecol. 1993;82(5):736-40.

6. Lasmar RB, Barrozo PRM, Dias R, Oliveira MAP. Submucous fibroids: A new presurgical classification (STEP-w) to evaluate the viability of hysteroscopic surgical treatment-Preliminary report.in: http://www.histeroscopia.med.br/. Access in:

7. Cravello L, Agostini A, Beerli M, Roger V, Bretelle F, Blanc B. Results of hysteroscopic myomectomy. Gynecol Obstet Fertil. 2004;32(9):825-8.

8. American College of Obstetricians and Gynecologists (ACOG). Surgical alternatives to hysterectomy in the management of leiomyomas. Washington (DC): American College of Obstetricians and Gynecologists (ACOG). 2000;10. (ACOG practice bulletin; no. 16).

9. Hallez JP. Single-stage total hysteroscopic myomectomies: indications, techniques, and results. Fertil Steril. 1995;63:703.

10. Emanuel MH, Wamsteker K, Hart AA. Long-term results of hysteroscopic myomectomy for abnormal uterine bleeding. Obstet Gynecol. 1999;93:743.

11. Derman SG, Rehnstrom J, Neuwirth RS. The longterm effectiveness of hysteroscopic treatment of menorrhagia and leiomyomas. Obstet Gynecol. 1991;77:591.

12. Munro MG, Brill AI, Parker WH. In: Berek, Jonathan Berek editor. Textbook ofBerek \& Novak's Gynecology, 14th Edition, New Delhi: Publisher Wolter Kluwer/ Lippincott Williams \& Wilkins. 2007:749-804.

13. Ioannis S, Aristotelis A, Antonios T, Panagiotis S, John B. Fertility rates after hysteroscopic treatment of submucous myomas depending on their type. Gynecological Surgery. 2006;3:206-10.

14. Fernandez H, Sefrioui O, Virelizier C. Hysteroscopic resection of submucosal myomas in patients with infertility. Hum Reprod. 2001;16:1489.

15. Vercellini P, Zaina B, Yaylayan L. Hysteroscopic myomectomy: long-term effects on menstrual pattern and fertility. Obstet Gynecol. 1999;94:341.

16. Donnez J, Jadoul P. What are the implications of myomas on fertility? A need for a debate? Hum Reprod. 2002;17:1424.

Cite this article as: Gupta P. Symptomatic submucous uterine fibroid: outcome of conservative surgery in a tertiary care hospital. Int J Reprod Contracept Obstet Gynecol 2016;5:1010-3. 